\title{
GMR
}

\section{A rapid and high-quality method for total RNA isolation from Haematococcus pluvialis}

\author{
Q.L. Luo ${ }^{1,2,3}$, K.P. Wang ${ }^{1}$, K. Xiao ${ }^{1,2}$, C.G. Wang' ${ }^{1}$ and Z.L. Hu ${ }^{1}$ \\ ${ }^{1}$ Shenzhen Key Laboratory of Marine Bioresource and Eco-Environmental Science, \\ Shenzhen Engineering Laboratory of Marine Algal Biotechnology, \\ College of Life Science, Shenzhen University, Shenzhen, China \\ ${ }^{2}$ Key Laboratory of Optoelectronic Devices and Systems of Ministry of \\ Education and Guangdong Province, College of Optoelectronic Engineering, \\ Shenzhen University, Shenzhen, China \\ ${ }^{3}$ Key Laboratory of Tropical Crop Biotechnology, Ministry of Agriculture, \\ Institute of Tropical Bioscience and Biotechnology, \\ Chinese Academy of Tropical Agricultural Science, Haikou, China \\ Corresponding authors: Z.L. Hu / C.G. Wang \\ E-mail: huzl@szu.edu.cn / charlesw@szu.edu.cn \\ Genet. Mol. Res. 16 (2): gmr16029614 \\ Received January 17, 2017 \\ Accepted March 16, 2017 \\ Published April 13, 2017 \\ DOI http://dx.doi.org/10.4238/gmr16029614
}

Copyright (C) 2017 The Authors. This is an open-access article distributed under the terms of the Creative Commons Attribution ShareAlike (CC BY-SA) 4.0 License.

ABSTRACT. Haematococcus pluvialis, as the most potential natural
source of astaxanthin, which is a powerful antioxidant with high
economic value, has attracted more and more scientific attention in
recent years. An in-depth understanding of the mechanism for how
$H$. pluvialis produces astaxanthin requires the intensive investigations
on its genetic information. In particular, many reported studies were
based on a variety of RNA analyses. However, it is difficult to extract
RNA with high quality and quantity from $H$. pluvialis, because of the
blockage from its thick cell wall and contamination by a large quantity
of pigments, polysaccharides, and lipids. Therefore, we proposed an
optimized Trizol-based RNA extraction method for $H$. pluvialis by
investigating the effect of cell wall broken ways, algal strains, and cell
growth status on total RNA isolation. Using this rapid, convenient, and

Genetics and Molecular Research 16 (2): gmr16029614 
cost-saving method, isolated $H$. pluvialis RNA had high quantity and quality (with an RNA integrity number of 7.0 and a concentration of $1604.1 \mathrm{ng} / \mu \mathrm{L}$ ) equivalent to that isolated by commercial kit, enabling its applications into downstream RNA analyses.

Key words: Haematococcus pluvialis; RNA extraction; RNA integrity; Statuses of cell growth; RT-PCR

\section{INTRODUCTION}

The unicellular alga Haematococcus pluvialisis is regarded as the natural source of high-valued carotenoid astaxanthin (Boussiba, 2000). Esterified astaxanthins were the predominant forms in $H$. pluvialis, exhibiting much stronger antioxidant activities than those from other organisms (Rao et al., 2013; Régnier et al., 2015). H. pluvialis was an ideal resource of lipid production and thus served as a suitable model organism for lipid metabolism research (Chen et al., 2015). To date, H. pluvialis is of economic importance and has drawn dramatic scientific attention in recent years.

Up to now, the genome of $H$. pluvialis is still unknown, which makes it difficult to investigate the molecular mechanism of secondary metabolism. With the development of metabolomics, proteomics, and transcriptomics, most key enzymes in astaxanthin synthesis have been characterized and studied (Gao et al., 2015). Through cDNA microarray, RNAseq, real-time quantitative PCR, and other biological techniques, the gene expression patterns under stresses such as nitrogen deprivation, high light irradiation, and high salinity have been analyzed (Kim et al., 2011; Gwak et al., 2014). The premise of these molecular characterizations requires RNA samples with high purity and quality.

Because $H$. pluvialis has a large quantity of pigments, polysaccharides and lipids (Recht et al., 2012), and thick cell wall in haematocyst cells, it is difficult to isolate RNA with high quality and sufficient quantity from $H$. pluvialis. In previous transcriptome studies, RNA of $H$. pluvialis was isolated by using commercial kits or Trizol (Kim et al., 2011; Gwak et al., 2014). Using commercial kits is efficient for studying mRNA, but has limitations when applied to small RNA and other non-coding RNA. The commercial kits were merely suitable for single kind of RNA extraction and unsuitable for total RNA. The extraction of total RNA by using Trizol also has shortcomings due to high contamination of genomic DNA and low yield of RNA due to severe degradation. Here, we proposed a modified Trizol method, which is efficient to isolate total RNA from $H$. pluvialis, with few contamination and degradation. Also, the effects of cell wall broken measures, algal strains, and status of cell growth on RNA isolation were discussed.

\section{MATERIAL AND METHODS}

\section{Algal strains and culture condition}

Four strains of $H$. pluvialis including 192.80, 34-1n, 34-1a, and 34-1b were purchased from Sammlung von Algenkulturen Gottingen Culture Collection of Algae. Samples were cultured in 250-mL Erlenmeyer flasks using permeable sealing membrane, statically incubated at $22^{\circ} \mathrm{C}$ under a light intensity of $25 \mu \mathrm{mol}$ photons $\cdot \mathrm{m}^{-2} \cdot \mathrm{s}^{-1}$ with a 12 -h light/12-h dark cycle.

Genetics and Molecular Research 16 (2): gmr16029614 
Three kinds of liquid media were used for cell growth, i.e., ESP, TAP, and MIX. Haematocyst cells were induced by high irradiation under $550 \mu \mathrm{mol}$ photons $\cdot \mathrm{m}^{-2} \cdot \mathrm{s}^{-1}$ for $6 \mathrm{~h}$.

\section{Modified RNA isolation methods}

Solution for RNA extraction was incubated with $0.1 \%$ diethylpyrocarbonate (Sigma) overnight at room temperature and then autoclaved for $20 \mathrm{~min}$. The plastic materials such as pipette tip and Eppendorf microcentrifuge tubes were of commercial RNase-free grade. Cylinders and flasks were baked at $180^{\circ} \mathrm{C}$ for $5 \mathrm{~h}$ before use. The sterilized work benches and centrifugation machines were wiped with RNaseZap (Ambion) to remove surface RNase. The powder-free plastic gloves were used during the entire RNA isolation procedure.

In our method, $2 \times 10^{5} \mathrm{H}$. pluvialis cells were collected by centrifugation at 10,000 $g$ for $1 \mathrm{~min}$. The samples were subsequently transferred to $1 \mathrm{~mL}$ Trizol buffer [2\% (w/v) polyvinylpolypyrrolidone (PVP40) (Sigma, MW 40,000), 1\% (v/v) $\beta$ mercaptoethanol]. After cells were broken with a vortex at the maximum speed for $1 \mathrm{~min}, 0.2 \mathrm{~mL}$ chloroform was added to each tube and mixed thoroughly. The tubes were then centrifuged at 10,000 g for $10 \mathrm{~min}$ at $4^{\circ} \mathrm{C}$. The supernatant was collected into a $1.5-\mathrm{mL}$ new RNase-Free microfuge tube and re-exacted by the equal volume of phenol:chloroform:isoamyl alcohol (25:24:1). Then, $50 \mathrm{U} / \mathrm{mL}$ DNase I (RNase free) was diluted in the supernatant, and incubated at $37^{\circ} \mathrm{C}$ for $10 \mathrm{~min}$. The DNase I and residual proteins in supernatant were removed by the equal volume of chloroform:isoamyl alcohol (24:1) and centrifuged. Total RNA was precipitated with $1 \mathrm{~mL}$ pre-chilled isopropanol for $10 \mathrm{~min}$ at $-20^{\circ} \mathrm{C}$. The RNA was washed twice with $75 \%$ ethanol, air-dried, dissolved in $60 \mu \mathrm{L} \mathrm{RNase-free} \mathrm{water,} \mathrm{and} \mathrm{stored} \mathrm{at}-80^{\circ} \mathrm{C}$. Other RNA extraction methods such as CTAB-LiCl, Trizol, and commercial kits were performed as the controls.

\section{Examination of RNA purity, yield and integrity}

Once the RNA was extracted, the integrity was evaluated by visualizing the 28S rRNA and 18S rRNA bands on a 1\% agarose gel. Marker DL2000 (TaKaRa) was used with the bands of 2000, 1000, 750, 500, 250, and $100 \mathrm{bp}$. The concentration of RNA was assessed with a spectrophotometer NanoDrop (BioPhotometer, Eppendorf, Hamburg, Germany) at wavelengths of 230, 260, and $280 \mathrm{~nm}$. Finally, RNA extractions were run in an Agilent 2100 Bioanalyzer (Agilent Technologies) for quality measurements. The bigger RNA integrity number (RIN) the less degradation was observed.

\section{Optimization of RNA extraction}

The effects of cell wall broken ways, strains, and cell growth status on RNA quality were discussed in the study. Five ways of cell wall broken were applied: oscillation with or without $0.1 \mathrm{~g}$ acid washed glass beads by a vortex at the maximum speed, ultrasonic wave, oscillation using FastPrep-24 (MP Biomedicals, USA) at $4000 \mathrm{~g}$ for $1 \mathrm{~min}$, frozen with liquid nitrogen, then grinded cells to the fine powder in a mortar. Four stains were used for RNA isolation. Cells at logarithmic growth stage cultured in TAP, MIX, and ESP were collected for RNA extraction.

Genetics and Molecular Research 16 (2): gmr16029614 


\section{Analysis of RNA by RT-PCR}

The total RNA extracted from $H$. pluvialis vegetable and haematocyst cells was converted to cDNA according to PrimeScript ${ }^{\mathrm{TM}}$ II 1st Strand cDNA Synthesis Kit (TaKaRa). Total RNA $(1 \mu \mathrm{g})$ was used as template using OligodT Primer $(50 \mu \mathrm{M})$, for $10 \mathrm{~min}$ at $70^{\circ} \mathrm{C}$, then mixed with $200 \mathrm{U}$ PrimeScript II RTase and $20 \mathrm{U}$ RNase inhibitor, and incubated for $1 \mathrm{~h}$ at $42^{\circ} \mathrm{C}$. The reaction was inactivated at $72^{\circ} \mathrm{C}$ for $10 \mathrm{~min}$.

The housekeeping gene $\beta$-actin (Huang et al., 2006) was amplified using specific primers (HpActin-F: 5'-AGCGGGAGATAGTGCGGGACA-3', HpActin-R: 5'-ATGCCCACCGCCTCAATGC-3'), as the cDNA template. Hpbkt1 gene was amplified using the primers (Hpbkt1-F: 5'-ACGTACATGCCCCACAAG-3', Hpbkt1-R: 5'-CAGGTCGAAGTGGTAGCAGGT-3'). PCRs were carried out in $20 \mu \mathrm{L}$ containing $1 \mu \mathrm{g}$ template (cDNA), $2 \mu \mathrm{L} 10 \mathrm{pM}$ primer mix (forward and reverse) and $10 \mu \mathrm{L}$ PCR mastermix. PCR mixture was denatured at $94^{\circ} \mathrm{C}$ for $5 \mathrm{~min}$, followed by 35 cycles of $30 \mathrm{~s}$ at $94^{\circ} \mathrm{C}, 30 \mathrm{~s}$ at $55^{\circ} \mathrm{C}$, and $30 \mathrm{~s}$ at $72^{\circ} \mathrm{C}$, and a final extension period at $72^{\circ} \mathrm{C}$ for $5 \mathrm{~min}$. PCR products were separated with $2 \%(\mathrm{w} / \mathrm{v})$ agarose gel, stained by ethidium bromide, and photographed by Gel Doc XR+ (BioRad, USA).

\section{RESULTS}

\section{High-quality total RNA isolated by our method}

Lanes 1 and 4 in Figure 1 show that the 28S rRNA band was equal to or brighter than that of the 18S rRNA, suggesting almost no RNA degradation. The RNA samples extracted by Trizol and CTAB-LiCl methods showed slight degradation as shown in lanes 2 and 3 (Figure 1). These suggest that high-quality RNAs from $H$. pluvialis cells were successfully isolated by our modified method as well as the commercial kit.

Spectrophotometer analysis by NanoDrop also revealed that our method as well as the commercial kit could isolate high purity and concentration RNA with $\mathrm{A}_{260} / \mathrm{A}_{280}$ and $\mathrm{A}_{260} / \mathrm{A}_{230}$ ratios greater than 2.0 (Table 1). The $\mathrm{A}_{260} / \mathrm{A}_{230}$ ratios of total RNA isolated by Trizol and CTABLiClmethods were both lower than 2.0, indicating contamination by polysaccharides, polyphenols, DNA, or proteins. The highest yield $(1604.1 \mathrm{ng} / \mu \mathrm{L})$ of RNA was obtained by our method.
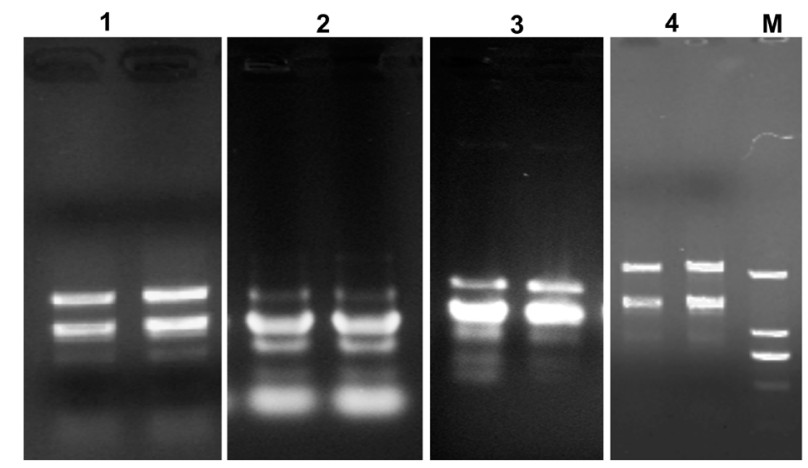

Figure 1. Total RNA isolated from Haematococcus pluvialis cells by four methods resolving through 1.0\% agarose gel. Lane M: 2-kb DNA marker, lane 1: commercial kit, lane 2: Trizol method, lane 3: CTAB-LiCl method, lane 4: modified Trizol method.

Genetics and Molecular Research 16 (2): gmr16029614 
Table 1. Spectrophotometer analysis of RNA isolated by four methods.

\begin{tabular}{l|l|c|c|c}
\hline Elements & Details & $\mathrm{A}_{260} / \mathrm{A}_{280}$ & $\mathrm{~A}_{260} / \mathrm{A}_{230}$ & $\mathrm{RNA}$ yields $(\mathrm{ng} / \mu \mathrm{L})$ \\
\hline \multirow{4}{*}{ Methods } & Modified method & 2.09 & 2.07 & 1604.1 \\
\cline { 2 - 5 } & CTAB-LiCl method & 1.98 & 1.32 & 946.2 \\
\cline { 2 - 5 } & Commercial kit & 2.05 & 2.08 & 1537.0 \\
\cline { 2 - 5 } & Trizol method & 1.87 & 1.78 & 1408.9 \\
\hline
\end{tabular}

\section{Optimization of RNA extraction method}

To optimize our modified RNA extraction method for H. pluvialis, the effects of cell wall broken ways, algal strains, and cell growth status on RNA extraction were investigated. The results are shown in Figure 2. The RNA extracted from cells treated with liquid $\mathrm{N}_{2}$ and subsequent grind has the best quantity and quality (Figure 2B, lane 5). In contrast, the RNA extracted from cells broken by FastPrep-24 was the worst (Figure 1, lane 2). The RNA examination using NanoDrop also showed the same results (Table 2). There were no differences among RNA extracted from four $H$. pluvialis strains (Figure 2A). All the RNA has an $\mathrm{A}_{260} / \mathrm{A}_{280}$ ratio over 1.8 and an $\mathrm{A}_{260} / \mathrm{A}_{230}$ ratio over 2.0, and a high concentration over $1.5 \mu \mathrm{g} /$ $\mu \mathrm{L}$ (Table 2). RNA isolated from cells cultured in Mix medium exhibited the best quality; the 28S rRNA band was brighter than that of $18 \mathrm{~S}$ rRNA, and 5S rRNA band was weak (Figure $2 \mathrm{C}$, lane 1). RNA purity and concentration were also determined by NanoDrop, showing that RNA extracted from cells grown in Mix medium has the highest $\mathrm{A}_{260} / \mathrm{A}_{280}$ and $\mathrm{A}_{260} / \mathrm{A}_{230}$ ratios (Table 2).

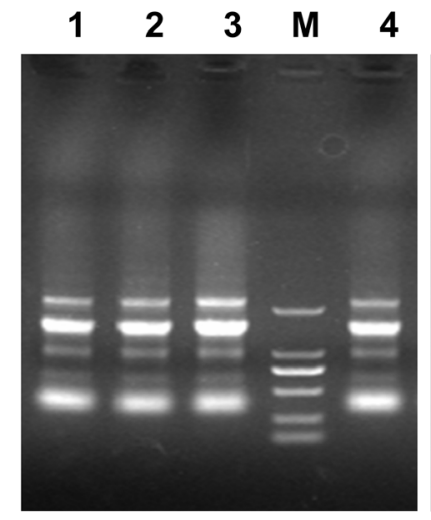

A

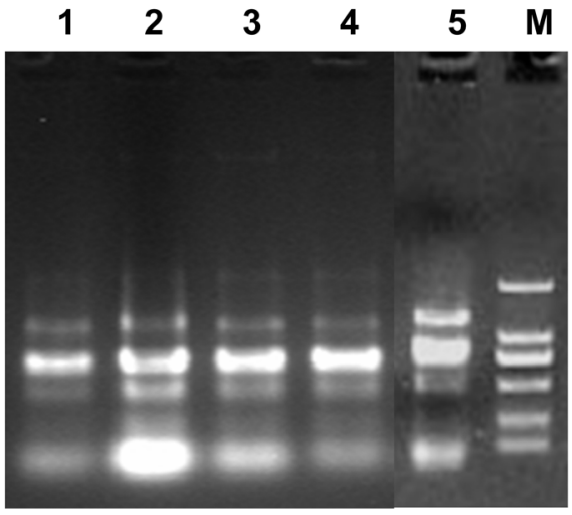

B

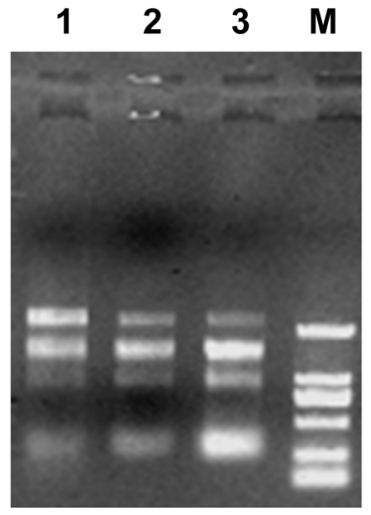

C

Figure 2. Electrophoretic analysis of RNA isolated from four Haematococcus pluvialis strains (A) broken by different ways $(\mathbf{B})$ and cultured in three media $(\mathbf{C})$. The RNA samples were separated on a $1.0 \%$ agarose gel containing ethidium bromide and photographed by Gel Doc XR+. Lane M: 2-kb DNA marker. A. RNA isolated from $H$. pluvialis strains: lane 1: 192.80, lane 2: 34-1n, lane 3: 34-1a, lane 4: 34-1b. B. RNA extracted was broken with ultrasonic wave (lane 1), FastPrep-24 (lane 2), oscillating on a vortexing machine with glass beads (lane 3), oscillating on a vortexing machine without glass beads (lane 4), by liquid N2 freezing and grinded to powder (lane 5). C. RNA isolated from cells cultured in media: lane 1: Mix, lane 2: TAP, lane 3: ESP medium. 
Table 2. Spectrophotometer results of RNA in extraction optimization.

\begin{tabular}{|c|c|c|c|c|}
\hline Elements & Details & $\mathrm{A}_{260} / \mathrm{A}_{280}$ & $\mathrm{~A}_{260} / \mathrm{A}_{230}$ & RNA yields (ng/ $\mu \mathrm{L})$ \\
\hline \multirow[t]{5}{*}{ Broken ways } & Ultrasonic wave & 1.54 & 1.62 & 3210.2 \\
\hline & FastPrep-24 & 1.62 & 1.57 & 2637.7 \\
\hline & Glass beads & 1.98 & 2.01 & 1847.3 \\
\hline & Just vortex & 1.96 & 2.04 & 1525.6 \\
\hline & Lipid N2 frozen & 2.18 & 2.16 & 1284.5 \\
\hline \multirow[t]{4}{*}{ Strains } & 192.80 & 1.89 & 2.13 & 1638.3 \\
\hline & $34-1 n$ & 1.89 & 2.14 & 1597.4 \\
\hline & $34-1 \mathrm{a}$ & 1.90 & 2.15 & 1610.5 \\
\hline & $34-1 b$ & 1.90 & 2.13 & 1705.8 \\
\hline \multirow[t]{3}{*}{ Medium } & ESP & 1.92 & 1.92 & 1490.4 \\
\hline & TAP & 1.85 & 1.53 & 1150.2 \\
\hline & Mix & 2.12 & 2.05 & 1508.1 \\
\hline
\end{tabular}

\section{RT-PCR analysis of RNA isolated by modified methods}

Total RNA was isolated from $H$. pluvialis 192.80 vegetable and haematocyst cells using our modified method. Beside the electrophoretic and spectrophotometer analyses, the RNA was also detected by Agilent 2100 Bioanalyzer. RNA on 1\% agarose had sharp bands (Figure $3 \mathrm{~A}$ ), $\mathrm{A}_{260} / \mathrm{A}_{280}$ and $\mathrm{A}_{260} / \mathrm{A}_{230}$ ratios were greater than 2.0, and RIN values was 7.0 (Figure $3 \mathrm{~B}$ ). All these results showed that RNA with high quality was successfully isolated by our modified method. After RT-PCR, the housekeeping gene HpActin was amplified successfully (Figure 3C). There was no difference from vegetable and haematocyst cells at the transcriptional levels of the HpActin gene. Also, the mRNA abundance of the Hpbkt1 gene was analyzed by encoding key enzyme HpBKT1 ( $\beta$-carotene ketolase) in astaxanthin biosynthesis in H. pluvialis (Meng et al., 2005). The Hpbkt1 gene was induced in haematocyst cells, indicating astaxanthin synthesis in cells. Our optimized protocol was suitable for RNA isolated from both vegetable and haematocyst cells.

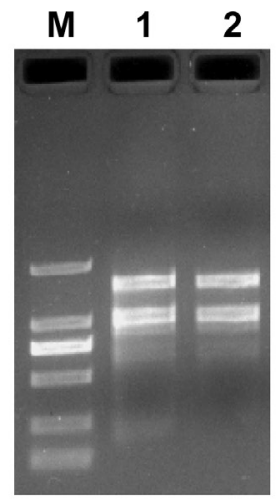

A

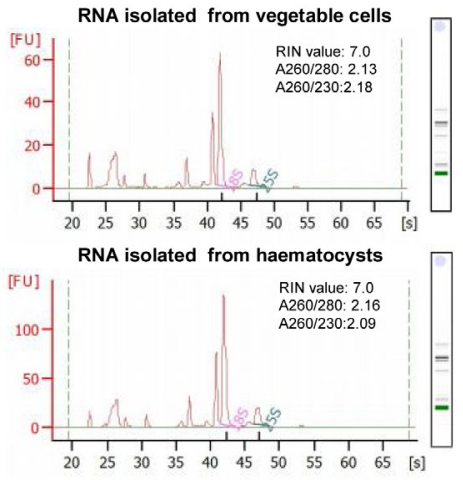

B

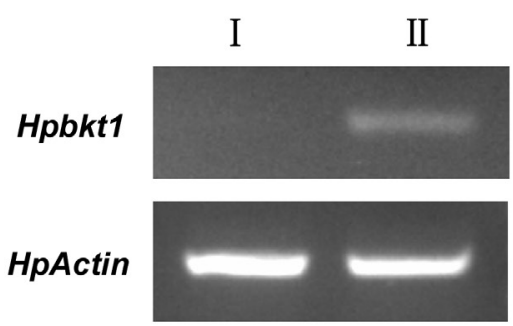

C

Figure 3. Electrophoretic (A), Bioanalyzer (B), and RT-PCR (C) analysis of RNA isolated by optimized procedure from vegetable and haematocyst cells. Lane M: 2-kb DNA marker, lane 1: RNA isolated from vegetable cells, lane 2: RNA isolated from haematocyst cells. RT-PCR of Hpbkt1 and HpActin genes was performed using the cDNA from vegetable cells (I) and haematocyst cells (II) as templates.

Genetics and Molecular Research 16 (2): gmr16029614 
High-quality method for total RNA

\section{DISCUSSION}

PVP40 and $\beta$-mercaptoethanol were commonly applied in total RNA extraction in high plants (Lan et al., 2013), but have not been used for RNA isolation in microalgae. PVP40 and $\beta$-mercaptoethanol were utilized in our method because they could bind more phenolic compounds to phenol, and then eliminate impurities in nucleic acids. DNAse I was added before precipitation of RNA to remove the contaminated genomic DNA and to make the RNA more pure, which was revealed by the phenol/chloroform extraction protocol.

Compared with the Chlamydomonas reinhardtii model microalgae, the H. pluvialis cells have thicker cell wall, especially in cysts (Wang et al., 2004). However, our results showed no significant differences in the RNA extracted by five different broken ways except liquid $\mathrm{N}_{2}$ (Figure 2B). Liquid $\mathrm{N}_{2}$ maybe a best way to break cells, but it requires a very large amount of $\mathrm{H}$. pluvialis cells (300 mg at least), making it not suitable for high throughput gene expression analysis. Other broken ways require fewer amounts of cells (more than $2 \times 10^{5}$ cells were enough). The results indicated one step of vortexing crush algae cells sufficiently, even without acid glass beads. It is simpler and quicker to use vortexing to break cells than other crush ways.

H. pluvialis cultured in Mix medium has the most biomass (Noroozi-M et al., 2012). The more cells were in a mitotic state, the more nucleic acids are synthesized. This may be a well explanation for why RNA extracted from cells in Mix medium was the best in terms of both quantity and quality. High-grade RNA could only be isolated from healthy cells.

In conclusion, we provided a rapid, convenience, efficient, and reproducible method to isolate high-quality total RNA from $H$. pluvialis. It is the first report of optimization of total RNA isolation for $H$. pluvialis cells. After comparison of effects such as cell wall broken ways, algal strains, status of cell growth, and isolation methods on quality of total RNA from H. pluvialis cells, we found that cell wall broken ways and algal strains did not affect RNA isolation. The status of $H$. pluvialis cell growth was the key element to determine both quantity and quality of total RNA. High RNA yield (bigger than $1.6 \mu \mathrm{g} / \mu \mathrm{L}$ ) was obtained from a small biomass (more than $2 \times 10^{5}$ cells). The total RNA was suitable for the subsequent molecular experiments, such as RT-PCR, RACE, RT-qPCR, and RNA Sequencing, among others. It may be used for isolating RNA from other microalgae species, which are rich in lipids, proteins, and secondary metabolites.

\section{Conflicts of interest}

The authors declare no conflict of interest.

\section{ACKNOWLEDGMENTS}

We would like to thank the anonymous reviewers for their constructive suggestions. Research supported by the National Natural Science Foundation of China (Grants \#31470389 and \#31470431); the Guangdong Natural Science Foundation (\#2014A030308017), the Shenzhen Grant Plan for Science \& Technology (\#JCYJ20160422171614147, \#JCYJ20150324141711583, \#JCYJ20120613112512654, \#JSGG20130411160539208, \#JSGG20141118114954828, and \#NYSW20140327010012), and the China Postdoctoral Science Foundation (\#2015M582403).

Genetics and Molecular Research 16 (2): gmr16029614 


\section{REFERENCES}

Boussiba S (2000). Carotenogenesis in the green alga Haematococcus pluvialis: Cellular physiology and stress response. Physiol. Plant. 108: 111-117. http://dx.doi.org/10.1034/j.1399-3054.2000.108002111.x

Chen G, Wang B, Han D, Sommerfeld M, et al. (2015). Molecular mechanisms of the coordination between astaxanthin and fatty acid biosynthesis in Haematococcus pluvialis (Chlorophyceae). Plant J. 81: 95-107. http://dx.doi.org/10.1111/ tpj. 12713

Gao Z, Meng C, Chen Y, Ahmed F, et al. (2015). Comparison of astaxanthin accumulation and biosynthesis gene expression of three Haematococcus pluvialis strains upon salinity stress. J. Appl. Phycol. 27: 1853-1860. http:// dx.doi.org/10.1007/s10811-014-0491-3

Gwak Y, Hwang YS, Wang B, Kim M, et al. (2014). Comparative analyses of lipidomes and transcriptomes reveal a concerted action of multiple defensive systems against photooxidative stress in Haematococcus pluvialis. J. Exp. Bot. 65: 4317-4334. http://dx.doi.org/10.1093/jxb/eru206

Huang JC, Chen F and Sandmann G (2006). Stress-related differential expression of multiple beta-carotene ketolase genes in the unicellular green alga Haematococcus pluvialis. J. Biotechnol. 122: 176-185. http://dx.doi.org/10.1016/j. jbiotec.2005.09.002

Kim DK, Hong SJ, Bae JH, Yim N, et al. (2011). Transcriptomic analysis of Haematococcus lacustris during astaxanthin accumulation under high irradiance and nutrient starvation. Biotechnol. Bioprocess Eng.; BBE 16: 698-705. http:// dx.doi.org/10.1007/s12257-011-0081-z

Lan T, Yao B, Shen Y and Wang X (2013). Isolation of high-quality total RNA from lipid-rich seeds. Anal. Biochem. 438: 11-13. http://dx.doi.org/10.1016/j.ab.2013.03.012

Meng CX, Teng CY, Jiang P, Qin S, et al. (2005). Cloning and characterization of beta-carotene ketolase gene promoter in Haematococcus pluvialis. Acta Biochim. Biophys. Sin. (Shanghai) 37: 270-275. http://dx.doi.org/10.1111/j.17457270.2005.00033.x

Noroozi-M OH, Napis S, Hejazi MA and Tan SG (2012). Comparative biodiversity and effect of different media on growth and astaxanthin content of nine geographical strains of Haematococcus pluvialis. Afr. J. Biotechnol. 11: 15049-15059.

Rao AR, Sindhuja HN, Dharmesh SM, Sankar KU, et al. (2013). Effective inhibition of skin cancer, tyrosinase, and antioxidative properties by astaxanthin and astaxanthin esters from the green alga Haematococcus pluvialis. J. Agric. Food Chem. 61: 3842-3851. http://dx.doi.org/10.1021/jf304609j

Recht L, Zarka A and Boussiba S (2012). Patterns of carbohydrate and fatty acid changes under nitrogen starvation in the microalgae Haematococcus pluvialis and Nannochloropsis sp. Appl. Microbiol. Biotechnol. 94: 1495-1503. http:// dx.doi.org/10.1007/s00253-012-3940-4

Régnier P, Bastias J, Rodriguez-Ruiz V, Caballero-Casero N, et al. (2015). Astaxanthin from Haematococcus pluvialis prevents oxidative stress on human endothelial cells without toxicity. Mar. Drugs 13: 2857-2874. http://dx.doi. org $/ 10.3390 / \mathrm{md} 13052857$

Wang SB, Hu Q, Sommerfeld M and Chen F (2004). Cell wall proteomics of the green alga Haematococcus pluvialis (Chlorophyceae). Proteomics 4: 692-708. http://dx.doi.org/10.1002/pmic.200300634

Genetics and Molecular Research 16 (2): gmr16029614 